\section{Three quarters of NHS dental practices failing to fill vacancies}

Around three quarters of NHS dental practice owners are finding it difficult to fill vacancies, according to a new survey carried out by the BDA.

The trade union said the results of its national survey of practice owners underlined its fears over the future of NHS dentistry.

Responses were gathered from 358 BDA members identified as practice owners in England from a survey of 1,544 members carried out between 8 June and 10 August 2018.

The results showed that $75 \%$ of NHS practice owners were struggling to fill vacancies last year, rising to $84 \%$ among those with the highest NHS commitments.

These figures have risen markedly in recent years, up from $50 \%$ in 2016 , rising to $68 \%$ in 2017.

The BDA said the figures reflected what it called 'growing disillusionment' with England's NHS dental system, with levels of NHS commitment now a key driver of low morale and low job satisfaction according to BDA surveys.

Official NHS sites were now recommending that patients undertake long journeys to get an appointment, such as new adult patients in Barrow-in-Furness being advised to travel to a practice in Whitehaven - a round trip of 90 miles.

BDA analysis had shown that some new patients across England were also facing round trips of more than 40 miles.

One dental practice in Barrow said it had permanent vacancies that had been left unfilled for five years and it was operating at quarter capacity.

Meanwhile, a leading recruitment agency had told the BDA that they had been unable to fill any posts advertised across Cumbria in the past 12 months. Even in London, agencies were saying they were unable to recruit NHS dentists with offers of (financial) golden handshakes.

Official data ${ }^{1}$ from NHS England had also shown that more than a million new adult patients tried and failed to secure access to NHS dental services last year.

BDA Vice Chair Eddie Crouch said: 'Patients are losing out because ministers wrongly assume NHS dentistry's survival is a forgone conclusion.

'The facts are if NHS practices can't fill vacancies then we can't treat NHS patients. Recruitment and retention are key, and a cash-strapped system that puts government targets ahead of patient care is now squeezing the workforce on both sides.

'Many patients will travel further or wait longer for care until this government stops punishing colleagues who commit themselves to the NHS.

\section{References}

1. NHS England. Summary of the Dental Results from the GP Patient Survey - January to March 2018. 2018. Available at https://www.england.nhs.uk/statistics/2018/08/09/gpps_dent_x1786_239846/(accessed March 2018).

\section{Extractions are main cause of patients' dental claims}

Extractions are the main reason that patients submit dental claims against practitioners, it has been confirmed by the Dental Defence Union (DDU).

The DDU has revealed the five areas of dental treatment that lead to the most claims for compensation.

During 2017, five aspects of dental care resulted in $80 \%$ of claims notified by GDPs to the DDU and of those, extractions accounted for around a quarter (24\%) of all claims, followed by root canal treatments (20\%) and caries and fillings with $17 \%$ of claims. Fourth and fifth place, respectively, were claims for periodontal disease (10\%) and for implant treatment (9\%).

The DDU said that although a dental professional was likely to face three clinical negligence claims in a 30-year career, only a minority of cases succeeded.

During 2018, the DDU's expert advice and guidance resulted in $69 \%$ of dental claims being successfully defended without the payment of compensation.

John Makin, Head of the DDU said: 'A lot has changed in the dental landscape in recent years such as the popularity of cosmetic treatments and technical advances in orthodontics and endodontics. Despite this, many of the allegations of clinical negligence made against DDU members relate to routine aspects of treatment such as extractions and fillings.

'If you face a claim you can be assured that our expert claims handlers and dentally qualified dento-legal advisers understand how stressful this is and the importance of mounting a robust defence of your position. Even though dental cases are often carefully selected by firms specialising in dental claims, we have an excellent track record of successfully defending cases and in the majority we make no compensation payment.'

The DDU advises dental professionals to take various steps to minimise risks, including:

- When obtaining consent take time to explain to patients, as part of the consent process, the material risks of treatment and the alternatives, including no treatment and make a note of the discussion in the clinical records

- Provide a written treatment plan and fee estimate and be sure to warn patients of the cost implications if circumstances change

- Recognise the limits of your own clinical skills and be prepared to refer the patient to an appropriate colleague if complications are likely

- Follow available relevant guidance to make sure your treatment would be supported by a responsible body of clinical opinion

- Ensure patients understand the importance of looking after their own oral health and record advice provided to patients on diet, oral hygiene, attendance patterns and factors such as smoking, drinking, medications and comorbidities

- Be open and honest with the patient if an unforeseen complication or error occurs during treatment. 